\title{
NGF-PC-AD CONNECTION
}

\author{
Some men see things as they are and say: 'Why?' \\ I dream things that never were and say: 'Why not!'
}

John F. Kennedy

In an elegant manner Viviana Triaca presented in this volume of Adipobiology her Homage to Rita Levi-Montalcini highlighting the significance of nerve growth factor (NGF) in the molecular mechanisms of Alzheimer's disease (AD) (1, also see Note in the References). This remarkable review generates a completely new direction in understanding some of the new and specific aspect of $\mathrm{AD}$ pathology, focusing on the NGF modulation of amyloid precursor protein (APP) processing and metabolism. Dr Triaca provides a paradigm shift from "classical" cholinergic to NGFcentered approach showing that the dysregulation of NGF-TrkA (receptor tyrosine kinase A) and proNGF-p75 ${ }^{\text {NTR }}$ signalling systems is a good candidate for being primus movens in the pathogenesis of $\mathrm{AD}(1)$.

Here we spotlights the possible involvement of primary cilium (PC) and PC-associated NGF signaling in the pathogenesis of AD.

As often occurs in the history of biomedical sciences, the presence or even the existence of a newly discovered cellular structure has been "enjoyed" a traditional neophobia. This was also the case with the PC. Hence within the last 15 years the emerging evidences have been demonstrating that in addition to their well-established roles in sight, smell, and mechanosensation, PC is a signaling hub for many physiologically, developmentally and diseased processes (2-5).

Almost all cells in the human body contain a single, primary cilium (PC). Cilia are plasma membrane-microtubule organelles represented by two major phenotypes: (i) motile, $9+2$ cilia, nu- merous per certain populations of cells, and (ii) non-motile, primary, $9+0$ cilia, single per almost all cell types including the neurons (2-5).

Although PC were observed around 1897 by Zimmerman in the renal epithelial cells (cited in 4), conclusive evidence of there existence required the introduction of the electron microscope for biological studies (6-8). Primary cilia control multiple cellular processes (9-14) such as fluid mechanical forces, calcium channel functioning, protein trafficking, and receptor-mediated signal transduction ( 15 for PC-p $75^{\mathrm{NTR}}$ connection). For the pioneering contributions of Poole and colleagues to cilium as cellular "cybernetic probe" functioning via its association with the Golgi complex, see 16,17, also 18.

The unprecedented interest in PC research came after the discovery that PC dysfunction or aciliogenesis is the culprit for many disorders now collectively termed primary ciliopathies, a selected list presented in Table 1. Intriguingly, various neuropsychiatric deseases including Alzheimer's disease (19-21) were recently also included in the list. In the same vein, obesity is a disorder associated with ciliopathies, such as Bardet-Biedl syndrome and Alström syndrome (22). And leptin, a prototypic adipocyte-secreted protein (adipokine), was implicated in obesity-associated ciliary dysfunction (23). Since obesity patients are prone to the development of $\mathrm{AD}$, and $\mathrm{APP}$ is expressed also in the adipose tissue (24), these data may further implicate PC dysfunction in $\mathrm{AD}$ neurodegeneration. 
Noteworthy, neurons contain both multiple spines on their dendrites as well as PC emanating from their soma. It was suggested that similar to dendritic spines (DS), another plasma membrane-cytoskeletal organelle (25), PC may function like a postsynaptic structure specialized in responding to "presynaptic" environmental stimuli $(26,27)$. Moreover, the formation and plasticity of DS require (i) brain-derived neurotrophic factor (BDNF), the first cousin of NGF, and (ii) not only actin and associated proteins, but also microtubules (28).

As mentioned above, PC expressing the panneurotrophin receptor $\mathrm{p} 75^{\mathrm{NTR}}$ has been found in $\mathrm{AD}$-associated granule cells of the adult hippocampal dentate gyrus in mice (15, see also 19$21,29)$. Since amyloid beta has been shown to bind $\mathrm{p} 75^{\mathrm{NTR}}$ and induce apoptotic pathway in neurons (1), PC-p75 ${ }^{\text {NTR }}$ connection might be implicated in the amyloid beta-driven neurodegeneration of AD (see 1 for IGF1 involvement in APP processing, and 30 for PC-IGF1 link).

As Dr Triaca notably states, a focus shift to "the discovery of blood or cerebrospinal fluid markers for early diagnosis, and early therapeutic intervention with modulators of APP processing" is a sign that the dynamics of $\mathrm{AD}$ research is undergoing remarkable plasticity. We expect that the next several years will delivered new insights into the significance of these amazing cellular molecules (NGF, p75 ${ }^{\text {NTR }}$, BDNF and IGF1) and organelles (PC and DS) in the pathogenesis of AD.

Why not!

Table 1. Selected disorders shown in $>200$ reports published in $2013^{*}$

\begin{tabular}{|l|l|}
\hline 1. Retinal dystrophy and degeneration & Many types \\
2. Neonatal and fetal death & A multitude of disorders \\
3. Bardet-Biedl syndrome(s) & Mesoaxialpolydactyly \\
4. Polycystic kidney disease and injuries & Autosomal dominant and recessive \\
5. Motor neurone disco-ordination & \\
6. Pre-invasive and invasive prostate cancer & \\
7. Joubert syndrome & Absence of well-formed cilia \\
8. Meckel-Gruber syndrome & Multi-organ dysgenesis \\
9. Nephronophthisis & Brain malformations \\
$\begin{array}{l}\text { 10. Lowe syndrome } \\
\text { 11. Biliary atresia }\end{array}$ & \\
$\begin{array}{l}\text { 12. Alström syndrome } \\
\text { 13. Cardiometabolic diseases }\end{array}$ & Obesity, insulin resistance \\
14. Mental retardation & Atherosclerosis, obesity, diabetes \\
15. Ventricular septal defects & \\
16. Jeune, Sensenbrenner, and Mainzer-Saldino & \\
chondrodysplasia & Disorientation of fibers \\
17. Lens fiber differentiation & \\
18. Cholangiocarcinoma & \\
19. Renal carcinoma & \\
20. Meier-Gorlin syndrome & \\
21. Birt-Hogg-Dube syndrome & \\
22. Alzheimer's disease & \\
\hline
\end{tabular}

* Modified from Wheatley (4). 


\section{Acknowledgments}

We wish to thank Denys Wheatley and Anthony Poole for brainand-heart friendship (BHF), also related to the research in ciliology. And apologize to colleagues whose work was not discussed or cited owing to space limitations.

\section{References}

1. Triaca V. Homage to Rita Levi-Montalcini. Molecular mechanisms of Alzheimer's disease: NGF modulation of APP processing. Adipobiology 2013; 5: 7-18.

Note: After Alois Alzheimer's clinical report of "presenile dementia" on 3 November 1906, the first Italian contributions to the histopathological and clinical description of Alzheimer's dementia were published by Gaetano Perusini in three papers between 1906 and 1911 (see Lucci B. The contribution of Gaetano Perusini to the definition of Alzheimer's disease. Ital J Neurol Sci 1998; 19: 49-52).

2. Zhang Q, Hu J, Ling K. Molecular views of Arf-like small GTPases in cilia and ciliopathies. Exp Cell Res 2013; 319: 2316-2322.

3. Wheatley DN. Nanobiology of the primary cilium - paradigm of a multifunctional nanomachine complex.Methods Cell Biol 2008; 90:139-156.

4. Wheatley DN. "Rediscovery" of a forgotten organelle, the primary cilium: the root cause of a plethora of disorders. Biomed Rev 2013; 24:1-7.

5. Dikranian K, Chaldakov GN. SOS for SOC*: The Renaissance of a seemingly ubiquitous organelle. Biomed Rev 2013; 24:9-10.

6. Dahl HA. Fine structure of cilia in rat cerebral cortex. Z Zelrorsch Microsk Anat 1963; 60:369-386.

7. Chaldakov GN. The ciliated smooth muscle and endothelial cell. Atherosclerosis 1985, 56:251-256.

8. Goranova V, Chaldakov GN. Ciliated fibroblasts and smooth muscle cells in the rat uterus. Experientia 1990; 46:488-489.

9. Verhey KJ, Dishinger J, Kee HL. Kinesin motors and primary cilia. Biochem Soc Trans 2011; 39:1120-1125.

10. Larsen J, Grigoriev I, Akhmanova A, Pedersen LB. Analysis of microtubule plus-end-tracking proteins in cilia. Methods Enzymol 2013; 524:105-122.

11. Singla V, Reiter JF. The primary cilium as the cell's antenna: signaling at a sensory organelle. Science 2006; 313:629-633.

12. Van der Heiden K, Egorova AD, Poelmann RE, Wentzel JJ, Hierck BP. Role for primary cilia as flow detectors in the cardiovascular system. Int Rev Cell Mol Biol 2011;290:87119.

13. Egorova AD, van der Heiden K, Poelmann RE, Hierck BP.
Primary cilia as biomechanical sensors in regulating endothelial function. Differentiation 2012;83:S56-61.

14. Delling M, DeCaen PG, Doerner JF, Febvay S, Clapham DE. Primary cilia are specialized calcium signalling organelles. Nature 2013; 504:311-314.

15. Chakravarthy B, Gaudet C, Ménard M, Atkinson T, Chiarini $\mathrm{A}, \mathrm{Dal}$ Prà I, et al. The p75 neurotrophin receptor is localized to primary cilia in adult murine hippocampal dentate gyrus granule cells. Biochem Biophys Res Commun 2010; 401:458-462.

16. Poole CA, Flint MH, Beaumont BW. Analysis of the morphology and function of primarycilia in connective tissues: a cellular cybernetic probe? Cell Motil 1985; 5,175-193.

17. McGlashan SR, Jensen CG, Poole CA. Localization of extracellular matrix receptors on the chondrocyte primary cilium. J Histochem Cytochem 2006;54:1005-1014.

18. Tenkova T, Chaldakov GN. Golgi-cilium complex in rabbit ciliary process cells. Cell Struct Funct 1988; 13:455-458.

19. Chakravarthy B, Gaudet C, Ménard M, Brown L, Atkinson T, Laferla FM, et al. Reduction of the immunostainable length of the hippocampal dentate granule cells' primary cilia in 3xAD-transgenic mice producing human $\mathrm{A} \beta(1$ 42) and tau. Biochem Biophys Res Commun 2012; 427:218222.

20. Armato U, Chakravarthy B, Pacchiana R, Whitfield JF. Alzheimer's disease: an update of the roles of receptors, astrocytes and primary cilia (review). Int J Mol Med 2013; 31:310.

21. Marley A, von Zastrow M. A simple cell-based assay reveals that diverse neuropsychiatric risk genes converge on primary cilia. PLoS 2012; 7:e46647.

22. Shalata A, Ramirez MC, Desnick RJ, Priedigkeit N, Buettner $\mathrm{C}$, Lindtner $\mathrm{C}$, et al. Morbid obesity resulting from inactivation of the ciliary protein CEP19 in humans and mice. Am J Hum Genet 2013; 93:1061-1071.

23. Berbari NF, Pasek RC, Malarkey EB, Yazdi SM, McNair $\mathrm{AD}$, Lewis WR, et al. Leptin resistance is a secondary consequence of the obesity in ciliopathy mutant mice. Proc Natl Acad Sci USA 2013; 110:7796-7801.

24. Puig KL, Floden AM, Adhikari R, Golovko MY, Combs CK. Amyloid precursor protein and proinflammatory changes are regulated in brain and adipose tissue in a murine model of high fat diet-induced obesity. PloS One 2012; 7:e30378.

25. Colgan LA, Yasuda R. Plasticity of dendritic spines: Subcompartmentalization of signaling. Annu Rev Physiol 2013 Nov 6.

26. Shaham S. Chemosensory organs as models of neuronal synapses. Nat Rev Neurosci 2010;11:212-217. 
27. Nechipurenko IV, Doroquez DB, Sengupta P. Primary cilia and dendritic spines: different but similar signaling compartments. Mol Cells 2013;36:288-303.

28. Gu J, L'Firestein B, Zheng JQ. Microtubules in dendritic spine development. J Neurosci 2008; 28:12120-12124.

29. Amador-Arjona A, Elliott J, Miller A, Ginbey A, Pazour GJ, Enikolopov G, et al. Primary cilia regulate proliferation of amplifying progenitors in adult hippocampus: implications for learning and memory. J Neurosci 2011; 31:99339944. doi: 10.1523/JNEUROSCI.1062-11.2011.

30. Yeh C, Li A, Chuang JZ, Saito M, Cáceres A, Sung CH. IGF-1 activates a cilium-localized noncanonical G $\beta \gamma$ signaling pathway that regulates cell-cycle progression. Dev Cell 2013;26:358-368. doi: 10.1016/j.devcel.2013.07.014.

\author{
George N. Chaldakov \\ Laboratory of Cell Biology \\ Department of Anatomy and Histology \\ Medical University \\ Varna, Bulgaria
}

\section{Krikor Dikranian}

Department of Anatomy and Neurobiology

Washington University School of Medicine

Saint Louis, MO, USA 